Department of Public Health and Epidemiology,

University of

Birmingham,

Edgbaston,

Birmingham

B15 2TT

Jeremy Hawker

consultant

epidemiologist

Department of

Public Health,

Sandwell Health

Authority, West

Bromwich B70 9LD

Iain Blair

consultant in

communicable disease

control.

Correspondence to:

B Olowokure,

Public Health

Laboratory Service

Communicable

Disease

Surveillance Centre,

West Midlands,

Heartlands

Hospital,

Birmingham

B9 5SS

bolowokure@

cdscwmid.demon.

co.uk

\section{Comment}

The reliability of surveillance systems can affect the observed effectiveness of public health interventions. H influenzae meningitis is a life threatening disease and most cases occur before the age of 2 years. ${ }^{3}$ In this study cases of $H$ influenzae meningitis in this age group were those most likely to be missed. The publicity surrounding the launch of the vaccine and the national study of vaccine failures ${ }^{4}$ might have been expected to improve reporting efficiency. However, we found that the introduction of the vaccine was associated with significantly increased underreporting, perhaps because of factors such as complacency following the success of the vaccine in reducing the incidence of the disease or an assumption that reporting to the British Paediatric Surveillance Unit was sufficient. These findings are relevant as continuing surveillance is needed to assess the effectiveness of the programme, identify vaccine failures, and monitor changes in predominant strains of the organism. A meningococcal vaccine is being introduced into the immunisation schedule in the United Kingdom. ${ }^{5}$ To measure the impact of this and other new vaccines accurately, the quality of the data sources for communicable disease surveillance must be ensured.

We are grateful to the Public Health Laboratory Service Communicable Disease Surveillance Centre and all the consult- ant microbiologists, consultants in communicable disease control, immunisation coordinators, consultant paediatricians, and medical records managers who contributed to this study by providing information on their patients. We are also grateful to the Oxford Vaccine Group for providing information on cases reported to it as part of the British Paediatric Surveillance Unit study of Hib conjugate vaccine failures.

Contributors: BO and NS conceived the study. BO collected data in the field and was responsible for data management and for preparation of the manuscript. JH and IB participated in the execution of the study. All authors contributed to data analysis and interpretation and participated in manuscript revision and approval of the final version. BO and NS are guarantors for the study.

Funding: This study was funded by a grant from the charities of the City of Coventry and partly funded by the Warwickshire Child Health Group.

Competing interests: None.

1 Hargreaves RM, Slack MPE, Howard AJ, Anderson E, Ramsay ME. Changing patterns of invasive Haemophilus influenzae disease in England and Wales after introduction of the Hib vaccination programme. BMJ 1996;312:160-1.

2 Macleod CA. Haemophilus influenzae: the efficiency of reporting invasive disease in England and Wales. Commun Dis Rep CDR Rev 1994;4:R13-16.

3 Nazareth B, Slack MPE, Howard AJ, Waight PA, Begg NT. A survey of invasive Haemophilus influenzae infections. Commun Dis Rep CDR Rev 1992;2:R13-16.

4 Salisbury DM. The introduction of Haemophilus influenzae type b immunization into the United Kingdom: practical steps to assure success. Pediatr Infect Dis J 1998;17:S136-9.

5 Wise J. UK introduces new meningitis C vaccine. BMJ 1999;319:278.

(Accepted 15 May 2000)

\title{
Reduced risk of hospital admission for childhood asthma among Scottish twins: record linkage study
}

David P Strachan, Sarah E Moran, Kevin McInneny, Mary Smalls

Department of

Public Health

Sciences,

St George's

Hospital Medical

School, London

SW17 0RE

David P Strachan

professor of

epidemiology

Sarah E Moran

statistician

Information and Statistics Division,

National Health

Service in Scotland,

Trinity Park House,

Edinburgh

EH5 3SO

Kevin McInneny

programmer

Mary Smalls

head of statistics

Correspondence to:

D P Strachan

d.strachan@sghms.

ac.uk

BMJ 2000;321:732-3
A recent study of Swedish army conscripts found a reduced prevalence of asthma and allergic rhinitis among twins. ${ }^{1}$ We analysed routine data on hospital admissions in Scotland to compare risks of asthma and other respiratory complaints among twins and singletons.

\section{Subjects, methods, and results}

We identified all twins born in Scotland during 1981-4 from computerised maternity records. Subsequent admissions of twins to Scottish hospitals during 1981-94 were ascertained by probability matching on the basis of date of birth, sex, and surname. This matching is considered $99 \%$ accurate for singletons, but for twins it is reliable only at the level of the pair: which twin is admitted cannot be identified with certainty.

We identified hospital admissions for respiratory disease (ICD-9 (international classification of diseases, 9th revision) codes 464, 466, 480-486, and 490-496) for all Scottish children born during 1981-4. Rates of hospital admission among singletons and twins up to 10 years of age were compared by cause and sex, assuming Poisson errors in the numerators.

Twins were significantly less likely than singletons to be admitted for respiratory diseases (table). This was attributable to a reduced risk of admission for asthma among twins (code 493) by more than half throughout the age range $0-10$ years. In contrast, twins were at significantly increased risk of admission for acute bronchitis and bronchiolitis (code 466). Admissions for other respiratory diseases were divided more equally between twins and singletons (table).

No significant differences were found between twins of the same or different sex in admission rates for any cause or all respiratory diseases combined. The relative difference in rates of admission with asthma for twins of the same sex compared with singletons was greater for males than for females, although this sex interaction was not significant.

\section{Comment}

Our record linkage study confirms that twins are at reduced risk of asthma but not of other respiratory diseases than are singletons. The twofold difference in rates for admissions with asthma between Scottish twins and singletons is greater than the difference in asthma prevalence (4.9\% versus 5.9\%) reported among Swedish army conscripts. ${ }^{1}$ Cases admitted to hospital possibly represent more severely affected patients among whom the "twin effect" is more influential. 
Annual admission rates per 1000 for twins and singletons born in Scotland 1981-4, admitted before age 10 years ( $\mathrm{n}=$ number of liveborn children)

\begin{tabular}{lccc} 
& Singletons & Twins & Rate ratio (95\% Cl) \\
\hline All twins and singletons: & $(\mathrm{n}=257871)$ & $(\mathrm{n}=5068 \dagger)$ & $0.47(0.39 \text { to } 0.57)^{* * *}$ \\
\hline Asthma & $4.45(11464)$ & $2.11(107)$ & $1.37(1.15 \text { to } 1.63)^{* * *}$ \\
\hline Acute bronchitis & $1.84(4757)$ & $2.53(128)$ & $0.97(0.83$ to 1.13$)$ \\
\hline Other respiratory diseases & $3.14(8094)$ & $3.04(154)$ & $0.81(0.74 \text { to } 0.90)^{* * *}$ \\
\hline All respiratory diseases & $9.43(24315)$ & $7.68(389)$ & $0.38(0.28 \text { to } 0.51)^{* * *}$ \\
\hline Male twins versus male singletons: & $(\mathrm{n}=132$ 006) & $(\mathrm{n}=1896)$ & $1.41(1.09 \text { to } 1.81)^{* *}$ \\
\hline Asthma & $5.62(7418)$ & $2.11(40)$ & $0.99(0.79$ to 1.24$)$ \\
\hline Acute bronchitis & $2.25(2968)$ & $3.16(60)$ & $0.76(0.68 \text { to } 0.90)^{* * *}$ \\
\hline Other respiratory diseases & $4.05(5341)$ & $4.01(76)$ & $0.58(0.41 \text { to } 0.81)^{* *}$ \\
\hline All respiratory diseases & $11.91(15727)$ & $9.28(176)$ & $1.59(1.16 \text { to } 2.18)^{* *}$ \\
\hline Female twins versus female singletons: & $(\mathrm{n}=125865)$ & $(\mathrm{n}=1724)$ & $1.03(0.76$ to 1.41$)$ \\
\hline Asthma & $3.21(4046)$ & $2.26(39)$ & $0.94(0.78$ to 1.12$)$ \\
\hline Acute bronchitis & $1.42(1789)$ & $2.26(39)$ & \\
\hline Other respiratory diseases & $2.19(2753)$ & $6.38(110)$ & $(\mathrm{n}=1430)$ \\
\hline All respiratory diseases & $6.82(858)$ & $2.45(35)$ & $0.55(0.40 \text { to } 0.76)^{* * *}$ \\
\hline Twins of different sex versus all singletons: & $(\mathrm{n}=257871)$ & $2.03(29)$ & $1.10(0.77$ to 1.58$)$ \\
\hline Asthma & $4.45(11464)$ & $2.73(39)$ & $0.87(0.64$ to 1.19$)$ \\
\hline Acute bronchitis & $1.84(4757)$ & $7.20(103)$ & $0.76(0.63 \text { to } 0.92)^{* *}$ \\
\hline Other respiratory diseases & $3.14(8094)$ & $9.43(24315)$ & \\
\hline All respiratory diseases & &
\end{tabular}

Number of admissions up to age 10 years in parentheses.

${ }^{\star \star} P \leqslant 0.01 ;{ }^{* \star *} P \leqslant 0.001$. †ncludes nine pairs of unknown sex.

The difference in rates for admission with asthma may have been exaggerated if the admission of one twin to hospital led to recognition and prophylactic treatment of asthma in the cotwin. Alternatively, hospital staff may prefer to label episodes of wheezing in twins as "acute bronchitis" rather than "asthma." Diagnostic transfer cannot be the whole explanation, however, because a reduced risk of admission among twins was still evident when all respiratory diagnoses were combined.

Although we were unable to distinguish monozygotic and dizygotic pairs, twin registry studies suggest a similar prevalence of asthma in monozygotic and dizygotic twins. ${ }^{2-4}$ Both types of twins tend to weigh less at birth than singletons, but low birthweight babies are generally at increased risk of asthma. Adjusting for birth weight would therefore accentuate rather than explain the twin effect, as was evident in the Swedish study. ${ }^{1}$

A more coherent explanation would be that twins have an extra sibling of the same age, and their reduced risk of asthma is a special case of the protective effect of large families on allergic disease. ${ }^{5}$ Sibship size is, however, more consistently related to hay fever and eczema than it is to asthma and wheezing. ${ }^{5}$ Swedish twins are also at a decreased risk of allergic rhinitis, but the effect of multiple gestation on asthma prevalence was not confined to conscripts with allergic rhinitis. ${ }^{1}$

We conclude that the effect of multiple gestation on risk of asthma is not readily explained by recognised risk factors. This deserves investigation as a clue to early developmental influences on asthma.

Contributors: DPS, MS, and KMcI designed the study. KMcI and SEM analysed the data. DPS took the lead in writing the paper and acts as guarantor.

Competing interests: None declared.

1 Bråbäck L, Hedberg A. Perinatal risk factors for atopic disease in conscripts. Clin Exp Allergy 1998;28:936-42

2 Nieminen MM, Kaprio J, Koskenvuo M. A population-based study of bronchial asthma in adult twin pairs. Chest 1991;100:70-5.
3 Duffy DL, Martin NG, Battistutta D, Hopper JL, Mathews JD. Genetics of asthma and hay fever in Australian twins. Am Rev Respir Dis $1990 ; 142: 1351-8$

4 Hopp RJ, Bewtra AK, Watt GD, Nair NM, Townley RG. Genetic analysis of allergic disease in twins. J Allergy Clin Immunol 1984;73:265-70.

5 Strachan DP. Allergy and family size: a riddle worth solving. Clin Exp Allergy 1997;27:235-6.

(Accepted 22 May 2000)

\section{Corrections and clarifications}

Science, medicine, and the future: Tolerance and autoimmunity

A transcription error occurred in figure 2 (p 94) in this article by Ian R Mackay (8 July 2000, pp 93-6). The cytokines released by Th2 T cells to stimulate B cell activation should be interleukin (not interferon) 4, 5, 6, 10, 13 (for correct version see http://bmj. com/cgi/content/full/321/7253/93/F2).

Randomised controlled trial of homoeopathy versus placebo in perennial allergic rhinitis with overview of four trial series

In this paper by Morag A Taylor and colleagues (19-26 August, pp 471-6) an inadvertent mix up over colours in one of the figures may have led to some confusion in interpreting the results. In the right hand column of figure 3 (p 474) the three pairs of points should not be black as shown: instead, the upper point in each pair should be blue (placebo) and the lower point white (homoeopathy).

The health risks of the UK's new asylum act Some readers might have had difficulty in accessing reference 3 in this editorial by Jim Connelly and Martin Schweiger (1 July, pp 5-6) because much of the detail was wrong. The correct reference is: Aldous J, Bardsley M, Daniell R, Gair R, Jacobson B, Lowdell C, et al. Refugee health in London: key issues for public health. London: Health of Londoners Project, 1999. (Also available at www.elcha.co.uk/holp/refugee.htm or from the Health of Londoners Project, tel 0207655 $6778 / 9)$ 